\title{
PMSE observations at three different frequencies in northern Europe during summer 1994
}

\author{
J. Bremer ${ }^{1}$, P. Hoffmann ${ }^{1}$, A. H. Manson ${ }^{2}$, C. E. Meek ${ }^{2}$, R. Rüster ${ }^{3}$, W. Singer ${ }^{1}$ \\ ${ }^{1}$ Institut für Atmosphärenphysik, D-18225 Kühlungsborn, Germany \\ ${ }^{2}$ Institute of Space and Atmospheric Studies, University of Saskatchewan, Saskatoon, S7N 5E2, Canada \\ 3 Max-Planck-Institut für Aeronomie, D-37189 Katlenburg-Lindau, Germany
}

Received: 3 January 1996/Revised: 27 May 1996/Accepted: 29 May 1996

\begin{abstract}
Simultaneous observations of polar mesosphere summer echoes (PMSE) have been carried out during summer 1994 in northern Norway using three radars on different frequencies: the ALOMAR SOUSY radar at Andenes on $53.5 \mathrm{MHz}$, the EISCAT VHF radar at Tromsø on $224 \mathrm{MHz}$ and the MF radar at Tromsø on $2.78 \mathrm{MHz}$. During the common measuring period in July/August 1994, PMSE could be detected at 224 and $53.5 \mathrm{MHz}$, and there are strong hints that PMSE also occur at $2.78 \mathrm{MHz}$. Reliable correlations between hourly backscattered power values indicate that the PMSE structures have zonal extensions of more than $130 \mathrm{~km}$ and can be detected at very different scales (half wavelength) between 0.67 (EISCAT VHF radar) and $54 \mathrm{~m}$ (MF radar). Using the wind values derived by the MF radar it can be shown that the mesospheric wind field influences the structure of PMSE. The diurnal variation of PMSE is strongly connected with tidal-wind components, whereas spatial differences of PMSE can partly be explained by the mean wind field.
\end{abstract}

\section{Introduction}

Since the first detection of polar mesosphere summer echoes (PMSE) by Ecklund and Balsley (1981) with a VHF radar $(50 \mathrm{MHz})$ at Poker Flat, Alaska, further observations have been made using radars in the VHF range, e.g. on $53.5 \mathrm{MHz}$ (Czechowsky et al., 1989) or on $224 \mathrm{MHz}$ (Hoppe et al., 1988), as well as in the UHF range on $933 \mathrm{MHz}$ (Röttger et al., 1990) and on $1.29 \mathrm{GHz}$ (Cho et al., 1992b). PMSE are normally observed during summer (middle of May until middle of August) at northern polar latitudes, whereas at the southern hemisphere no, or only weak PMSE have been found until now (Balsley et al., 1995).

Correspondence to: J. Bremer
The physical reasons for the PMSE are not yet known in all details. According to the turbulence theory of Hocking (1985), the irregularities necessary for the scattering of VHF radar waves from the mesopause region should be in the viscous subrange of the neutral turbulence spectrum, thus preventing strong radar backscatter. However, large water cluster ions (Kelley et al., 1987), large charged aerosols (Cho et al., 1992a) or small ice particles (Klostermeyer, 1994b) may shift the turbulence-driven spectrum of irregularities in the electron density to markedly shorter scales than those observed in the neutral turbulence itself. As these different particles preferentially occur in the cold summer mesopause region they may play an important role in the PMSE phenomena observed in the VHF range. According to Hoppe et al. (1994), ion density structures observed by a rocket instrument can also explain PMSE at 46.8 and $224 \mathrm{MHz}$. In the UHF range enhanced Thomson scatter by dressed dust particles was suggested by Havnes et al. (1990); however, Hagfors (1992) demonstrated that this effect is too small. Klostermeyer (1994a) discussed the effect of small ice particles on Thomson scattering. In the HF and MF range, however, partial reflections should be the dominant scattering mechanism. Comprehensive reviews of PMSE observations and theories can be found in Cho and Kelley (1993) and Röttger (1994).

Simultaneous PMSE observations at different frequencies have been carried out by Kelley et al. (1990) during the MAC/SINE campaign with the SOUSY radar at $53.5 \mathrm{MHz}$ near Andenes and the EISCAT VHF radar (224 MHz) at Tromsø (mainly on 15 July 1987, 1155-1320 UT). Kirkwood et al. (1995) reported more extensive simultaneous measurements during the NLC-91 campaign with the CUPRI radar $(46.9 \mathrm{MHz})$ at Esrange near Kiruna and EISCAT VHF radar at Tromsø between 24 July and 10 August 1991 (72-h common measurements). In both cases significant connections between PMSE features have been observed in spite of the different frequencies used and distances of about 130 or $200 \mathrm{~km}$ between the observation sites. 
Table 1. Technical parameters of the radar systems used in summer 1994

\begin{tabular}{llll}
\hline & EISCAT VHF & ALOMAR SOUSY & MF-Tromsø \\
\hline Coordinates & $69.6^{\circ} \mathrm{N} ; 19.2^{\circ} \mathrm{E}$ & $69.3^{\circ} \mathrm{N} ; 16.0^{\circ} \mathrm{E}$ & $69.6^{\circ} \mathrm{N} ; 19.2^{\circ} \mathrm{E}$ \\
Peak power & $1.5 \mathrm{MW}$ & $150 \mathrm{~kW}$ & $50 \mathrm{~kW}$ \\
Frequency & $224 \mathrm{MHz}$ & $53.5 \mathrm{MHz}$ & $2.78 \mathrm{kHz}$ \\
Height range & $72-95 \mathrm{~km}$ & $77-95 \mathrm{~km}$ & $43-136 \mathrm{~km}$ \\
Height resolution & $300 \mathrm{~m}$ & $150 \mathrm{~m}$ & $3 \mathrm{~km}$ \\
Time resolution & $2 \mathrm{~s}$ & $36 \mathrm{~s}$ & $5 \mathrm{~min}$ \\
Beam width & $1.7^{\circ} \mathrm{N}-\mathrm{S}, 0.6^{\circ} \mathrm{E}-\mathrm{W}$ & $6.5^{\circ}$ & Vertical \\
Beam direction & Vertical & Vertical $, \mathrm{S}, \mathrm{W}\left(8^{\circ}\right.$ off-zenith) & $25 / 7 / 94-11 / 8 / 1994$ \\
Observation time & $25 / 7 / 94-10 / 8 / 1994$ & $23 / 7 / 94-22 / 8 / 1994$ & \\
\hline
\end{tabular}

In this paper we will report on simultaneous PMSE observations during July and August 1994 with three different radar systems in northern Norway: the ALOMAR SOUSY radar on $53.5 \mathrm{MHz}$ located at Andenes, the EISCAT VHF radar $(224 \mathrm{MHz})$ at Tromsø, as well as the Canadian/Norwegian MF radar $(2.78 \mathrm{MHz})$ at Tromsø. Some important details of these experiments are summarized in Table 1. With the ALOMAR SOUSY radar we have nearly continuous observations during the period between 23 July and 22 August, and with the MF radar between 25 July and 1 August, whereas with the EISCAT VHF radar the measurements are usually restricted to $4-5 \mathrm{~h}$ around local midnight between 25 July and 10 August. First results mainly restricted to the PMSE observations with the EISCAT VHF and the ALOMAR SOUSY radar have recently been published by Bremer et al. (1996). Here these investigations will be extended by the PMSE data detected with the MF radar.

\section{Experimental results}

As demonstrated in detail by Bremer et al. (1996), during the main part of the PMSE observation time in summer 1994 the solar activity was relatively small, with a solar $10.7-\mathrm{cm}$ radio flux of $\mathrm{F} 10.7 \approx 75$ s.f.u. (solar flux unit: $10^{-22} \mathrm{Wm}^{-2} \mathrm{~Hz}^{-1}$ ). Only near 14 August was a small enhancement in the solar activity observed $($ F10.7 =94). Also, the geomagnetic activity was relatively undisturbed, only interrupted on 28 July by a very small event $(\mathrm{Ap}=17)$ and near 13 and 14 August by a small disturbance $(A p=27)$. The latter event is connected with enhanced cosmic noise absorption at polar latitudes due to increasing particle precipitation.

In Fig. 1 the signal-to-noise ratio (SNR) of the backscattered power of the ALOMAR SOUSY radar is shown as a function of height and time; a seasonal and diurnal variation is evident. The SNR values decreased during the observation time, and after 20 August almost no PMSE were detected. The geomagnetic disturbance after $13 \mathrm{Au}-$ gust could be the reason for the small PMSE recovery between about 13 and 18 August.

The diurnal variation of PMSE in Fig. 1, which is more clearly to be seen in the upper part of Fig. 11, is character- ized by a pronounced maximum near noon, a secondary maximum near midnight, a very marked minimum in the evening and a small minimum in the morning hours. This diurnal variation is also reflected in the mean SNR profiles shown in Fig. 2 for typical time-intervals during the day. Especially remarkable differences occur between the PMSE maximum near noon and the clearly reduced values in the evening. A very similar diurnal variation of PMSE has also been derived by Williams et al. (1995) using EISCAT observations with the VHF Common Programme CP6 during the summers of 1988, 1990 and 1991. In general, PMSE were mainly observed at heights between about 82 and $88 \mathrm{~km}$. From Fig. 1 the height-interval with PMSE is more extended at the beginning of the observation period and markedly decreased at the end. The seasonal trend demonstrates reductions in both the maximum backscattered power and the height-interval with PMSE observations.

The mean SNR profiles of Fig. 2 show a double-peak structure, with maxima near 84 and $86 \mathrm{~km}$. Such double layers are also often observed during individual PMSE events.

\subsection{Comparison of ALOMAR SOUSY and EISCAT observations}

For all $84 \mathrm{~h}$ of simultaneous observations with the EISCAT and ALOMAR SOUSY radar we calculated hourly mean SNR values over a height-interval of $3 \mathrm{~km}$ for five heights between 79 and $91 \mathrm{~km}$. In Fig. 3 the correlograms of these data sets are shown for the heights 82,85 and $88 \mathrm{~km}$, together with the corresponding best-fit lines. The scatter of the hourly values increases with height, resulting in a decreasing correlation coefficient $R$. The correlation coefficients for all five heights investigated are shown in Fig. 4 (circles connected with solid lines). Using the Fisher F-test, a significant correlation with a reliability level of more than $99 \%$ could be found between about 80.5 and $87.5 \mathrm{~km}$ taking into consideration the persistence tendency of the hourly SNR values (Taubenheim, 1969). By a correlation analysis between SNR values of the ALOMAR SOUSY radar at a fixed height and EISCAT observations at different heights (Bremer et al., 1996), the maximum correlation has been found for 


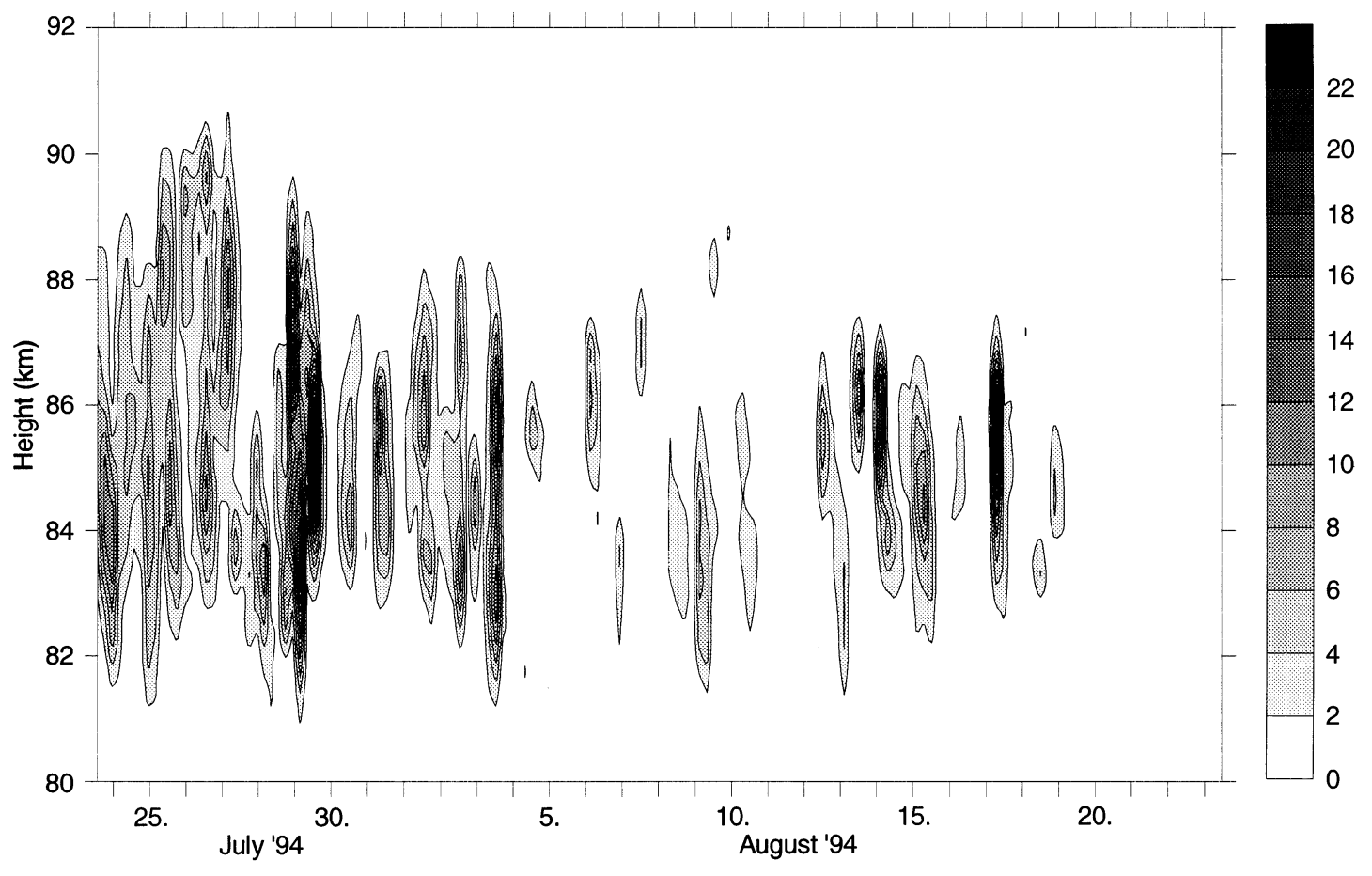

Fig. 1. Mean backscattered echo power measured with the ALOMAR SOUSY radar as a function of height and time

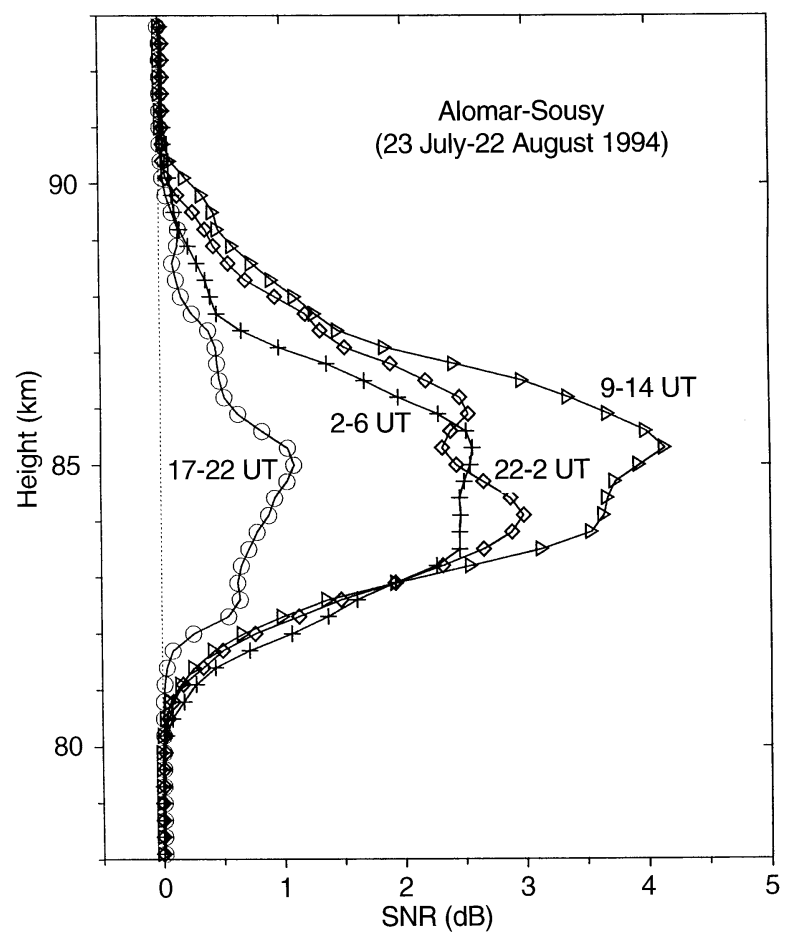

Fig. 2. Mean profiles of the SNR obtained by ALOMAR SOUSY radar observations for different time-intervals during the day

$h($ EISCAT $)=h($ ALOMAR SOUSY $)+0.4 \mathrm{~km}$. The corresponding correlation coefficients using hourly SNR values with these slightly different height-intervals are presented in Fig. 4 by crosses connected with dashed lines.
As expected these correlation values are only slightly higher than those of the corresponding values obtained for equal heights.

\subsection{Comparison of ALOMAR SOUSY with MF-radar observations}

Until now it has been very difficult to detect PMSE structures with MF radars. Using the PRE (partial reflection experiment) radar on $2.78 \mathrm{MHz}$ at Tromsø, Hoppe et al. (1990) did not find such echoes. Only Vlaskov et al. (1995) reported some indirect indications of PMSEsimilar features in their MF-radar data at $2.7 \mathrm{MHz}$ near Murmansk. In this paper the first more directly detected PMSE structures will be presented using the observations made by the upgraded (1993) Canadian real-time wind system operating with the Tromsø MFradar.

In Fig. 5 hourly SNR profiles of the ALOMAR SOUSY data (solid lines) are compared with corresponding profiles of the MF radar (circles connected with dotted lines) for the period between 20 UT on 28 July and 14 UT on 29 July 1994. There are some general differences between both series of profiles. Whereas the ALOMAR SOUSY radar detects PMSE only in the known heightinterval between about 80 and $90 \mathrm{~km}$, the SNR profiles of the MF-radar are more extended. This behaviour is caused on the one hand by the reduced height resolution of the MF-radar $(3 \mathrm{~km})$, but on the other hand by the fact that the SNR data consists of two components: the normal non-PMSE and a possibly PMSE-caused part. The former is known to be considerable (Manson and Meek, 1989). In principle it is impossible to separate exactly both these components. But it seems that some peaks in 


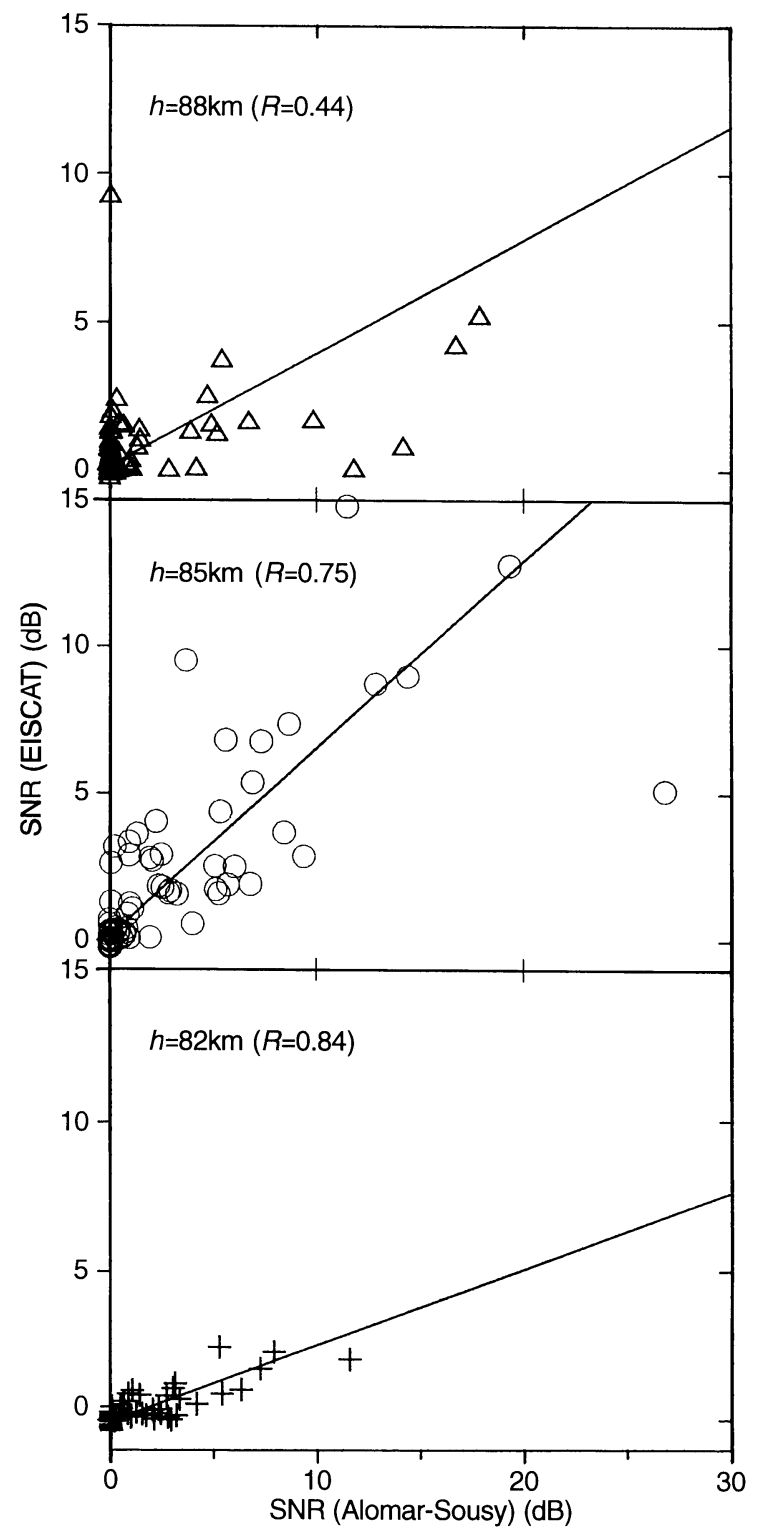

Fig. 3. Correlograms of hourly SNR values derived from EISCAT and ALOMAR SOUSY observations for different heights together with the best-fit lines

the MF profiles are connected with the PMSE structures deduced from the VHF radar. Increases in MF-radar SNR near $85 \mathrm{~km}$ correspond well to those enhancements in ALOMAR SOUSY observations (centred on 1-2 and 12-13 UT). Sometimes the peaks in MF and VHF profiles appear at the same height (e.g. 22-24 and 7-9 UT) but more often the MF peaks seem to occur at lower heights than in the VHF profiles (0-6 and 9-14 UT). In the VHF and UHF range PMSE are often observed with extremely small spectra (Röttger et al., 1988, 1990). In the MF measurements, however, spectra are not calculated. Therefore, an identification of PMSE by their spectral form is impossible in the MF range.

In Fig. 6 a correlogram is shown of MF and VHF mean values (time-interval: $1 \mathrm{~h}$, height-interval: $3 \mathrm{~km}$ ) at an

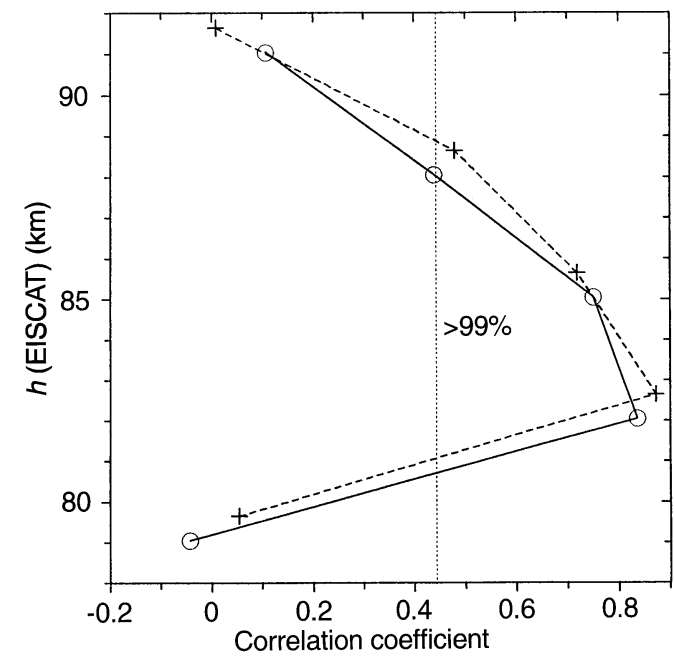

Fig. 4. Correlation between hourly SNR values obtained by EISCAT and ALOMAR SOUSY observations as a function of height using SNR values at equal heights (solid lines) and at different heights (dashed line: $h($ EISCAT $)=h($ ALOMAR SOUSY) $+0.4 \mathrm{~km})$

altitude of $h=82 \mathrm{~km}$, using all 456 data points (19 days) which are available from simultaneous observations. Comparing the results of Figs. 3 and 6, the scatter between the MF and ALOMAR SOUSY data is markedly more extended than between EISCAT and ALOMAR SOUSY values. The main reason for this enhanced scatter should be the non-PMSE-caused part in the SNR values of the MF radar (but note that MF noise levels can change drastically, and this also effects the SNR). In Fig. 7 the correlation coefficients using MF and ALOMAR SOUSY data at the same heights are plotted against heights (circles connected with solid lines). Comparing these data with the corresponding results between ALOMAR SOUSY and EISCAT data in Fig. 4, the correlation between ALOMAR SOUSY and MF data is markedly weaker. Nevertheless, this correlation is significant between 80 and $87 \mathrm{~km}$ due to the large number of data included in the analysis. Here the same statistical-significance test has been carried out as in Fig. 4.

In Fig. 8 the ALOMAR SOUSY data at different heights are correlated with the MF data at a constant height $(h=82 \mathrm{~km})$. The maximum correlation is obtained for $h$ (ALOMAR SOUSY $)=84.3 \mathrm{~km}$. We found a corresponding result if we used MF data at $85 \mathrm{~km}$. Here we obtained a maximum correlation with ALOMAR SOUSY data at $h=87.3 \mathrm{~km}$. Using this height difference of $2.3 \mathrm{~km}$, the dashed curve in Fig. 7 was derived by a correlation between SNR values of ALOMAR SOUSY radar at a height $h+2.3 \mathrm{~km}$ with MF values at height $h$. The correlation coefficients represented by the dashed curve are markedly higher than those of the solid curve, thus confirming the result of Fig. 8, that the SNR values of the ALOMAR SOUSY radar correlate best with MFradar data if a height difference of $2.3 \mathrm{~km}$ between both data sets is introduced. 


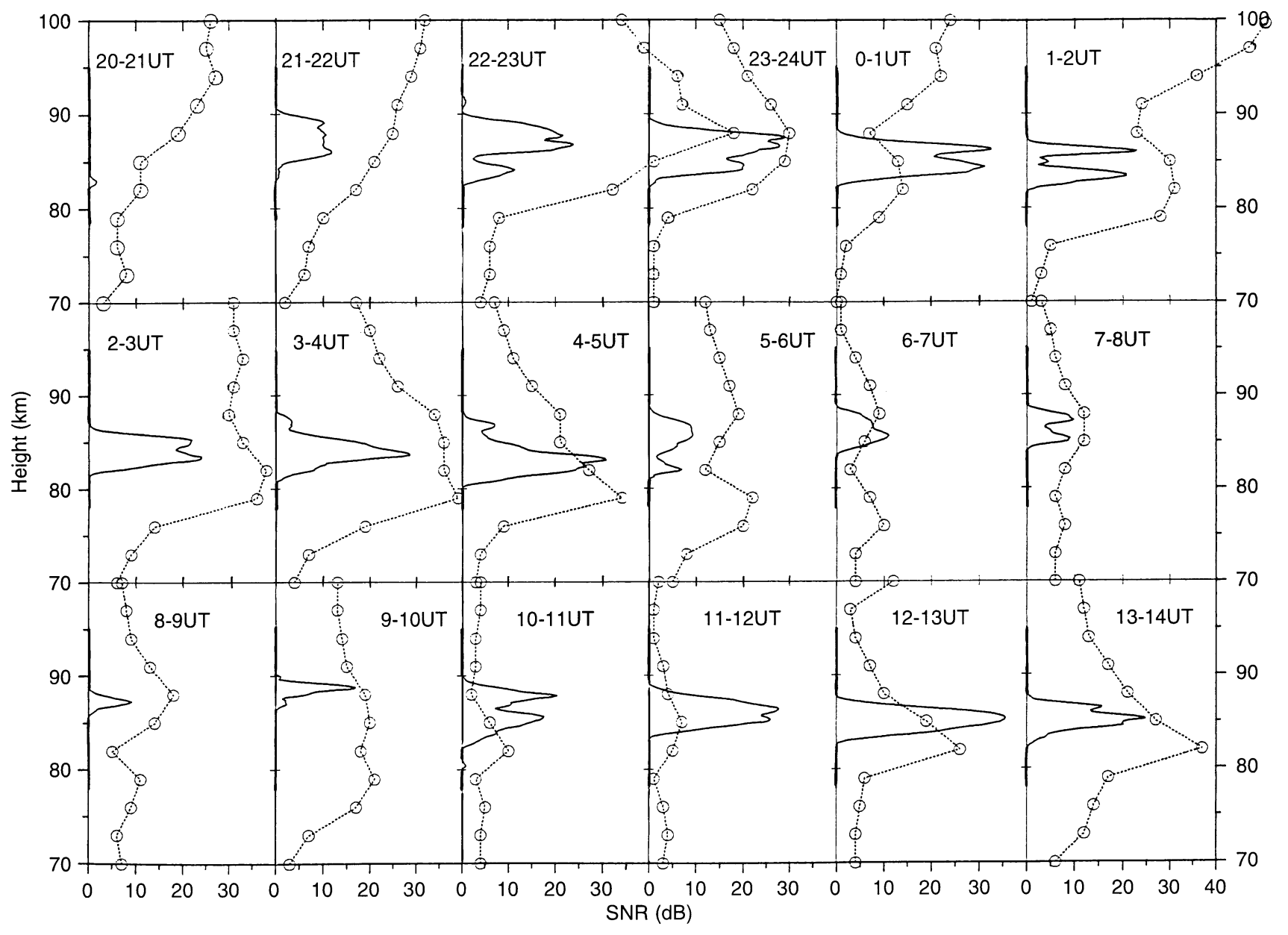

Fig. 5. Mean hourly SNR profiles deduced from ALOMAR SOUSY (solid lines) and MF-radar observations (dotted lines) on 28-29 July 1994

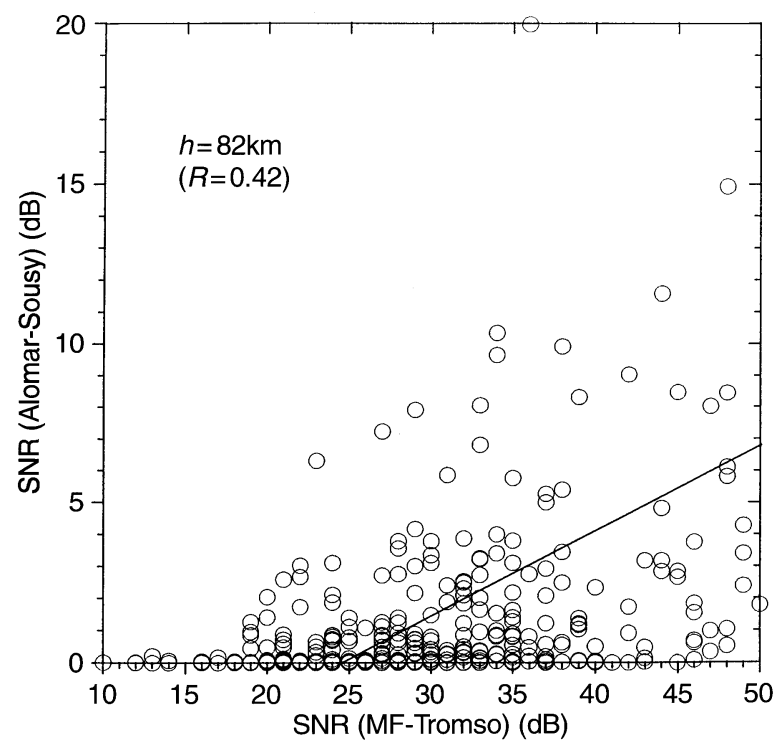

Fig. 6. Correlogram of hourly SNR values derived from ALOMAR SOUSY and MF-radar observations at an altitude of $82 \mathrm{~km}$ together with the best-fit line

\subsection{Comparison of EISCAT VHF with MF-radar observations}

For 84 mean SNR values (time-interval: $1 \mathrm{~h}$, height-interval: $3 \mathrm{~km}$ ) of EISCAT VHF and corresponding MF values a correlation analysis has been carried out in a similar way as described in Sects. 2.1 and 2.2. In Fig. 9 the correlation coefficients are shown against height using data at the same heights (solid curve) as well as data with a height difference $h($ EISCAT $)-h(\mathrm{MF})=2.5 \mathrm{~km}$ (dashed curve). Whereas the correlation coefficients for equal heights are not reliable with more than $99 \%$, the correlation between data with a height difference of $2.5 \mathrm{~km}$ is highly reliable, with more than $99 \%$ significance between 81 and $86 \mathrm{~km}$.

The height difference of $2.5 \mathrm{~km}$ has been derived by the correlation analysis between the MF data at a fixed height and SNR data of EISCAT observations at different heights. In Fig. 10 the result of this analysis is shown for the fixed $\mathrm{MF}$ height $h(\mathrm{MF})=82 \mathrm{~km}$ with a maximum correlation at $h($ EISCAT $)=85.6 \mathrm{~km}$, thus resulting in a height difference $\Delta h=3.6 \mathrm{~km}$. Using other fixed $\mathrm{MF}$ heights, however, we obtained smaller differences $[h(\mathrm{MF})$ $=79 \mathrm{~km}: \Delta h=2.9 \mathrm{~km} ; \quad h(\mathrm{MF})=85 \mathrm{~m}: \Delta h=0.9 \mathrm{~km}]$. These different results may be caused by the smaller number of hourly mean values available in this analysis $(N=84)$ in contrast to the same analysis between 


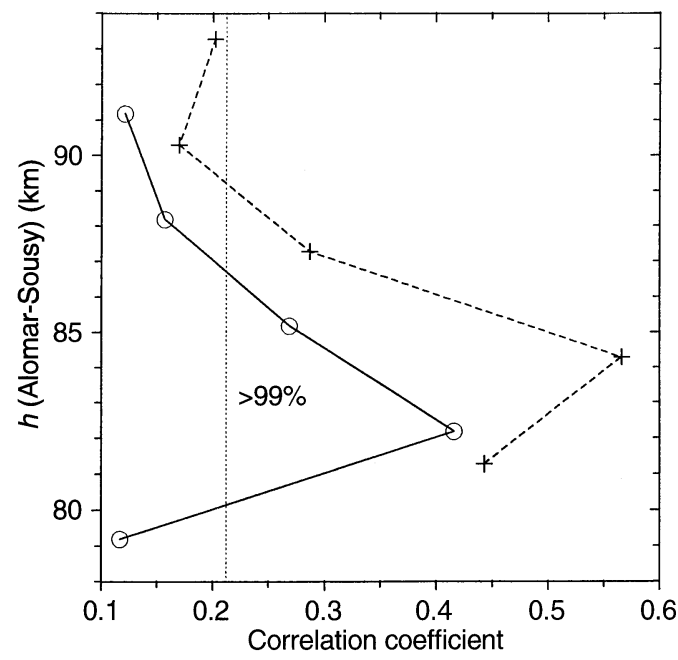

Fig. 7. Correlation between hourly SNR values obtained by ALOMAR SOUSY and MF-radar observations as a function of height using SNR values at equal heights (solid line) and at different heights (dashed line: $h(\mathrm{ALOMAR}$ SOUSY $)=h(\mathrm{MF})+2.3 \mathrm{~km})$

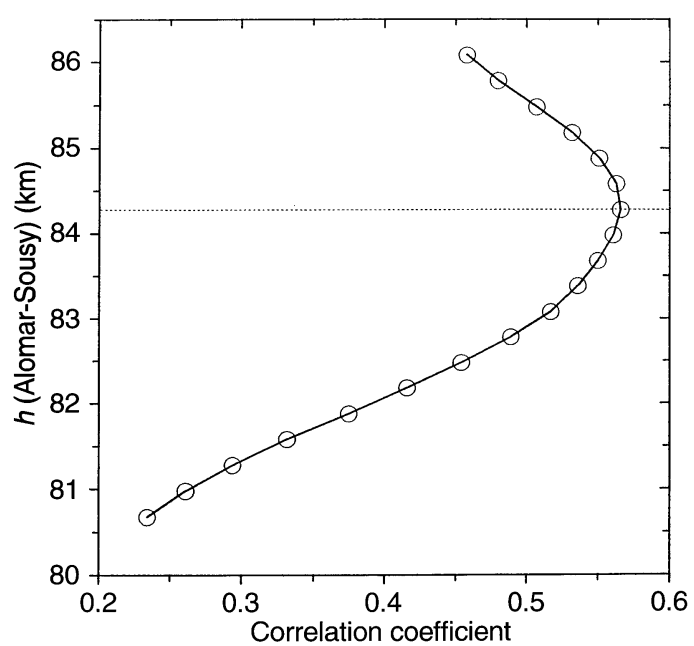

Fig. 8. Correlation between hourly SNR values measured with the ALOMAR SOUSY radar at different heights and data of the MF radar at a constant height $(h=82 \mathrm{~km})$

ALOMAR SOUSY and MF radar data $(N=456)$ in Sect. 2.2. We believe that the mean value of $\Delta h=2.5 \mathrm{~km}$ is the best approximation for the mean height difference of maximum correlation between SNR values detected with the co-located EISCAT VHF and MF radar.

\section{Discussion}

\subsection{Heights of PMSE}

During summer 1994 simultaneous PMSE observations have been carried out with the co-located EISCAT VHF radar $(224 \mathrm{MHz})$ and the Canadian/Norwegian MF radar $(2.78 \mathrm{MHz})$ at Tromsø, as well as with the ALOMAR

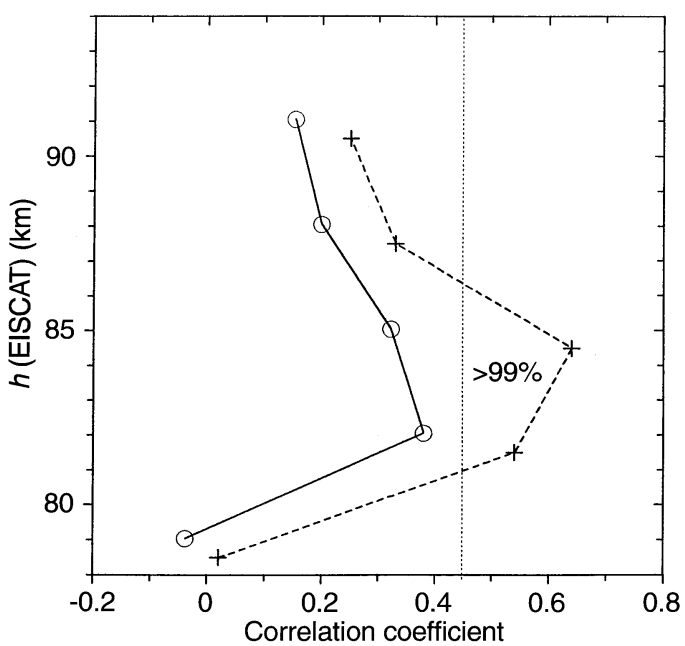

Fig. 9. Correlation between hourly SNR values deduced from EISCAT VHF and MF-radar observations as a function of height using SNR values at equal heights (solid line) and at different heights (dashed line: $h(\mathrm{EISCAT})=h(\mathrm{MF})+2.5 \mathrm{~km})$

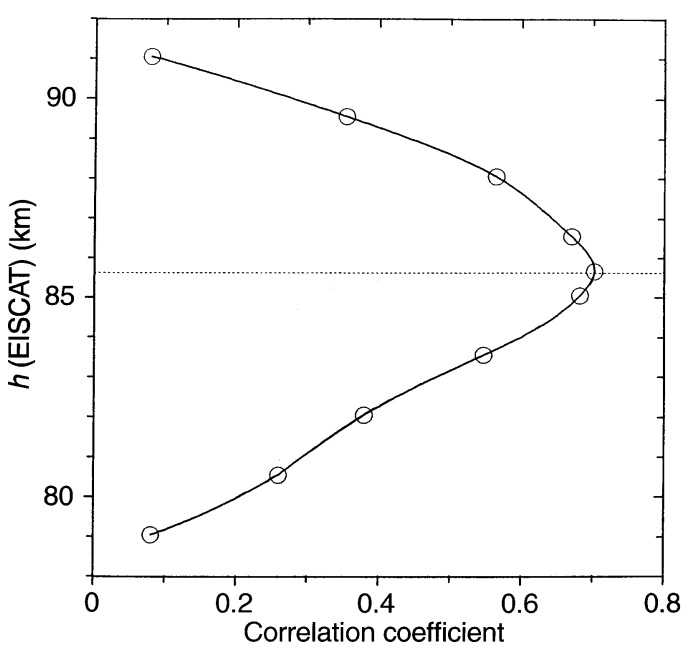

Fig. 10. Correlation between hourly SNR values observed with the EISCAT radar at different heights and the data of the MF radar at a constant height $(h=82 \mathrm{~km})$

SOUSY radar $(53.5 \mathrm{MHz})$ at Andenes. As shown above (Sects. 2.1, 2.2 and 2.3) the PMSE structures observed with these three different radars show significant correlation if hourly mean values of the backscattered power are used. Best correlation has been found between EISCAT VHF and ALOMAR SOUSY observations in spite of the spatial difference of $130 \mathrm{~km}$ between both measuring places. Also, the height difference where maximum correlation was detected [ $h$ (EISCAT) $-h($ ALOMAR SOUSY $)=$ $0.4 \mathrm{~km}]$ is very small. Therefore, it can be stated that the scales which cause strong radar backscatter for both sets of equipment (half wavelength $=0.67 \mathrm{~m}$ for EISCAT and $2.8 \mathrm{~m}$ for ALOMAR SOUSY) occur during PMSE conditions at nearly the same height (assuming a thin, nontilted scattering layer). An essential reason for the good 
correlation between the PMSE observations by these two VHF radars is that during summertime both radars seldom detect the (weaker) non-PMSE structures. Only the EISCAT VHF radar is slightly affected by some incoherent-scatter echoes at the upper part of the PMSE region (Hoppe et al., 1988; Bremer et al., 1996). The SNR values of the MF radar, however, are strongly influenced by non-PMSE echoes. This fact is well known and is the basis of "partial-reflection" measurements during the whole year for heights above 60 or $70 \mathrm{~km}$ up to the bottom of the E layer (Manson and Meek, 1989). In spite of this ubiquitous non-PMSE part, we obtained a statistically significant correlation between MF observations and ALOMAR SOUSY, as well as EISCAT data. Maximum correlation was found, however, if we used SNR values of the MF radar at lower heights than at the VHF radars. The height differences are $2.3 \mathrm{~km}$ for the ALOMAR SOUSY data and about $2.5 \mathrm{~km}$ for EISCAT data. The reason that the PMSE echoes were apparently detected by the MF radar at lower heights is not yet clear. It could be that the PMSE scales in the MF range (half wavelength = $54 \mathrm{~m}$ ) are more pronounced at lower heights than PMSE at shorter scales. There are for instance some indications of partially reflected echoes at very low altitudes detected by a dynasonde in summer 1995 at Tromsø, near or even below $80-\mathrm{km}$ altitude (private communication with $\mathrm{M}$. Rietveld, 1995). A detailed comparison of these data with PMSE observations of the EISCAT VHF radar is, however, not yet available.

Comments on height calibration are relevant here. For the EISCAT and ALOMAR SOUSY radars the timedelays in the equipment (mainly filters of the receiver and antenna feed lines) were carefully measured and taken into account in the detected echo heights. The EISCAT VHF radar was also compared with the EISCAT UHF system using backscattered echoes from a satellite (private communication by M. Rietveld, 1996). The agreement between heights observed by both EISCAT radars was better than $100 \mathrm{~m}$. Therefore, we believe that the accuracy of both the ALOMAR SOUSY and the EISCAT VHF radars is in the order of $100 \mathrm{~m}$. The MF Tromsø receiving system is virtually identical to that at Saskatoon, the height calibration of which was the subject of exhaustive study during 1993-1994. As Phillips et al. (1994) show, a combination of laboratory measurements and detection from a high-altitude balloon was used. With this calibration the preferred height for the OI (558-nm) emission layer, following wind comparisons with the radar and FPI (Fabry-Perot interferometer) systems, was $97 \mathrm{~km}$, which is the generally preferred height for this layer. The same calibration then, was applied to the Tromsø MF radar. The differences between heights of the PMSE found by the three radar systems are therefore interesting and certainly worthy of further assessment. For example, the electronic components that differ between Tromsø and Saskatoon (the transmitter and transmission lines) could contribute approximately $1 \mathrm{~km}$ in the right direction, but probably not $2.5 \mathrm{~km}$. Detailed comparisons of wind profiles deduced from the ALOMAR SOUSY and MF radar are in preparation, and these should help to resolve any remaining discrepancy. Our present conclusion is that up to $2.5 \mathrm{~km}$ a real difference exists between heights of PMSE detected by the MF radar (lower height) and the ALOMAR SOUSY/EISCAT radars. On the other hand, if the PMSE layers were at a constant height over the several weeks, a height error of up to $\pm 1.5 \mathrm{~km}$ would be possible, because the "calibrated MF height" refers to the centre of a 3-km-range resolution bin.

\subsection{Diurnal variation of PMSE and tides}

Hints of a pronounced diurnal variation of PMSE were found by Hoppe et al. (1988) and Czechowsky et al. (1989). These authors, as well as Rüster (1995), Cho and Morley (1995) and Williams et al. (1995), suggest an influence of atmospheric tides on the variation of the PMSE. Therefore, in the upper part of Fig. 11 the mean diurnal variation of SNR derived from the ALOMAR SOUSY observations between 23 July and 22 August 1994 is shown for an altitude of $85 \mathrm{~km}$, whereas in the lower part of this figure the mean zonal wind presented is derived from MF-radar measurements taken between 17 July and 11 August 1994 (the MF transmitter failed on 12 August), also for a height of $85 \mathrm{~km}$. Clearly, a strongly negative correlation between both data sets exists. The mean SNR as well as the mean zonal wind of Fig. 11 is dominated by a diurnal and a semidiurnal variation, as documented by the results of a harmonic analysis shown in Table 2 . As expected, marked diurnal and semidiurnal components were found in both parameters. A phase shift of $180^{\circ}$ is observed between the zonal components of the diurnal and semidiurnal tides and the respective backscattered power. A physical explanation of the negative correlation

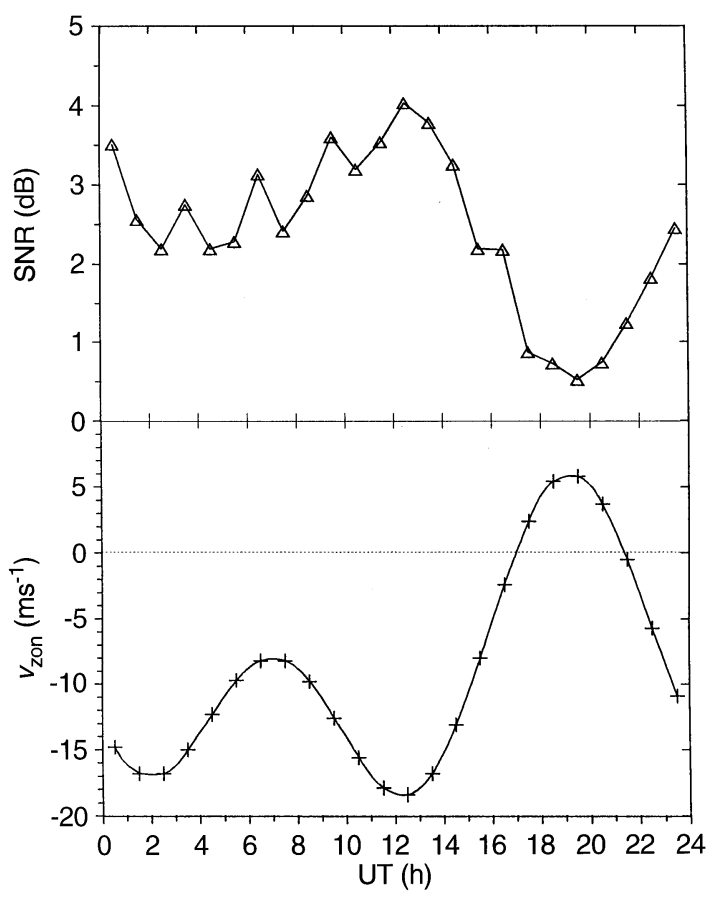

Fig. 11. Comparison of the mean diurnal variation of SNR obtained by ALOMAR SOUSY measurements with the zonal wind deduced from MF-radar observations at $85-\mathrm{km}$ altitude 
Table 2. Diurnal and semidiurnal tidal components of the mean SNR after ALOMAR SOUSY and zonal-wind data from MF-radar observations at an altitude of $85 \mathrm{~km}$ shown in Fig. 11

\begin{tabular}{llllll}
\hline & $\mathrm{A}_{0}$ & $\mathrm{~A}_{24}$ & $\varphi_{24}$ & $\mathrm{~A}_{12}$ & $\varphi_{12}$ \\
\hline $\mathrm{SNR}$ & $2.42 \mathrm{~dB}$ & $1.01 \mathrm{~dB}$ & $10.0 \mathrm{LMT}$ & $0.87 \mathrm{~dB}$ & $1.8 \mathrm{LMT}$ \\
$v_{\text {zon }}$ & $-9.0 \mathrm{~m} \mathrm{~s}^{-1}$ & $7.0 \mathrm{~m} \mathrm{~s}^{-1}$ & $20.5 \mathrm{LMT}$ & $8.0 \mathrm{~m} \mathrm{~s}^{-1}$ & $8.1 \mathrm{LMT}$ \\
\hline
\end{tabular}

can be given if we assume that the phase of the tidal zonal wind components has the same phase as the tidal temperature perturbances. According to a comprehensive numerical modelling of tides by Aso (1993), this is at least true for the diurnal tidal mode. Assuming that this relation is also valid for the semidiurnal tide, we find maximum PMSE during times of minimum temperature and vice versa. As discussed in Sect. 1 of this paper, low temperatures in the mesopause region are favourable conditions for large water cluster ions, large charged aerosols and small ice particles which may support PMSE backscatter. From the results presented here, negative correlation between the backscattered power and the tidal components of the zonal wind [or temperature according to Aso (1993)] supports the assumption that these particles are mainly responsible for production of PMSE. It is, however, difficult to decide which type of particle is most important for the PMSE phenomena. If water cluster ions dominate then a phase shift between backscattered power and temperature near $180^{\circ}$ is to be expected, due to the fast water-cluster forming processes.

If, however, ice particles or charged aerosols are more dominating, then an additional time-delay $\Delta \varphi$ is expected, resulting in a total phase shift of $180^{\circ}+\Delta \varphi$. Cho and Morley (1995) found from a cross-spectral analysis of PMSE and vertical-wind observations with the Poker Flat radar during 1979 and 1985 an additional delay $\Delta \varphi=10^{\circ}-20^{\circ}$ for tidal components. This result is very close to the results presented here. Rüster (1995) found in his investigations of PMSE observations in June 1987 at Andenes a phase-delay of about $180^{\circ}$ between the northward-directed radial velocity and the backscattered power. For the interpretation of this observation a phase shift $\Delta \varphi \approx 90^{\circ}$ is necessary between the wave-induced minimum temperature and the maximum radar echo intensity. According to Jensen and Thomas (1994), temperature oscillations lead to variations in ice-crystal radii, which are phase shifted by about $90^{\circ}$. In principle all three results agree, only the additional phase-delay is different. Further investigations are necessary to solve this question.

Another possible explanation of the results presented in Fig. 11 considers the meridional wind. The diurnal variation for the meridional wind component (not shown) has oscillations which are of similar magnitude to the zonal but lead it by about $3 \mathrm{~h}$ (as expected for the semidiurnal tide). The advection of colder/warmer air from the north/south also modifies the PMSE structures. The phase-lag for the PMSE response is consistent with this; viz. the meridional wind changes from northwards to southwards at about the time when the zonal wind maximizes eastwards, and at this time the air over the radar is that which has been transported from the furthest north.

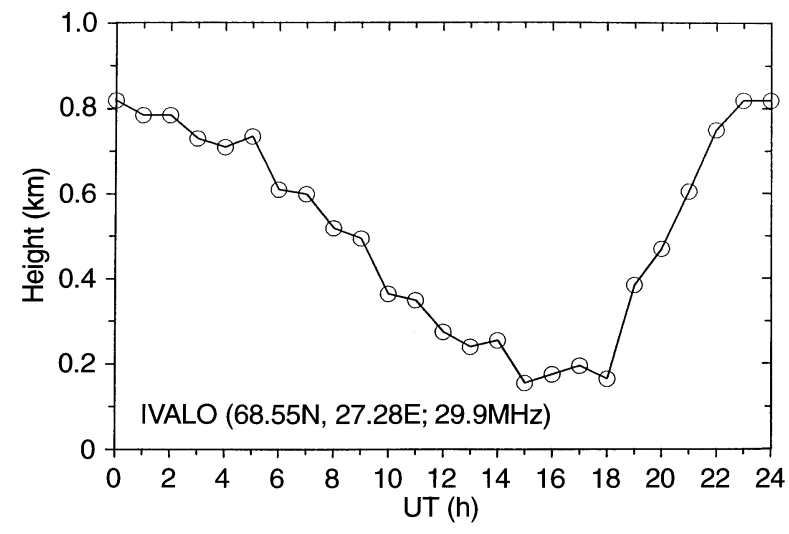

Fig. 12. Mean diurnal variation of cosmic noise absorption observed at the Finnish station Ivalo during July/August 1994 (from Ionospheric Absorption Data, Geophysical Observatory Sodankylä)

\subsection{PMSE and precipitating particles}

Besides the tidal components of the mesospheric wind field, the diurnal variation of the ionization near the mesopause region could influence the diurnal variation of PMSE. Therefore, in Fig. 12 the mean monthly variation of cosmic noise absorption (CNA) observed at the Finnish stations Ivalo during July/August 1994 is presented. The CNA of this station qualitatively describes the variation of ionization in the polar $\mathrm{D}$ region. Comparing the CNA variation with the mean SNR variation (upper part of Fig. 11), it can be seen that nearly no similarities exist. Only the clear ionization minimum in the evening could partly be connected with the evening SNR minimum. However, the CNA minimum seems to be about $3 \mathrm{~h}$ earlier than the corresponding minimum in the PMSE observations. Therefore, the influence of the diurnal variation of ionization should be only a second-order effect. Day-to-day variability of PMSE, however, may be modulated by ionization effects due to geomagnetic disturbances. As mentioned, the small recovery of SNR in connection with the small geomagnetic disturbance near 13-14 August 1994 (see Fig. 2) may be an example.

\subsection{PMSE and mean mesospheric wind field}

PMSE structures should be influenced by tidal waves, as already demonstrated, by gravity waves (e.g. Williams et al., 1989; Hall, 1990; Bremer et al., 1995), but also by the mean mesospheric wind field (Kelley et al., 1990; Bremer et al., 1996). The latter authors used observations with the EISCAT VHF radar at Tromsø and the SOUSY radar (Kelley et al., 1990) or the ALOMAR SOUSY radar (Bremer et al., 1996) at Andenes. In both cases some signatures have been found that the PMSE structures are partly transported by the mean wind field. This feature can also be demonstrated if we use observations made with the east and west beams of the ALOMAR SOUSY radar. With an off-zenith angle of $8^{\circ}$ of the oblique beams (see Table 1), the mean radar volumes at $85-\mathrm{km}$ altitude 

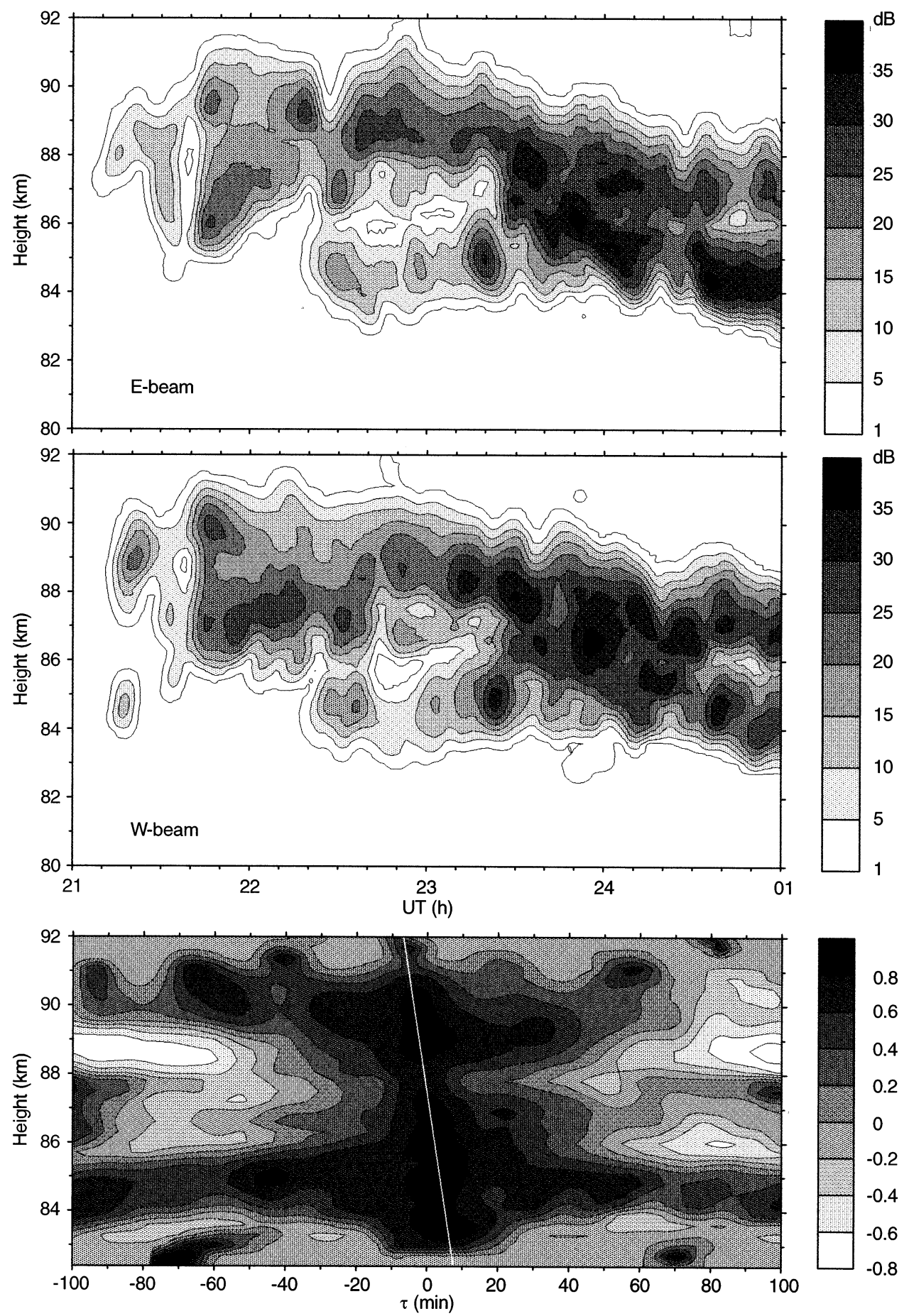

Fig. 13. PMSE event observed with the oblique $\mathrm{E}$ and $\mathrm{W}$ beams of the ALOMAR SOUSY radar on 28-29 July 1994 (upper and middle part) and crosscorrelation function between $\operatorname{SNR}(t)$ of the E beam and $\operatorname{SNR}(t+\tau)$ of the $\mathrm{W}$ beam as a function of height and timedelay $\tau$ (lower part). The white line approximately connects areas with maximum correlation are spaced by about $24 \mathrm{~km}$. In the upper part of Fig. 13 the PMSE event on 28-29 July 1994 is presented for both beams, whereas in the lower part the results of a crosscorrelation analysis between both observations are presented as a function of height and time-delay $\tau$. The dark areas with a correlation coefficient greater than 0.8 are connected by a white line. Below about $86 \mathrm{~km}$ maximum correlation has been observed with a positive time-delay $\tau$ and above this height with a negative delay. These different time-delays are caused by the zonal mean wind as shown by the wind profile in Fig. 14 (the meridional winds are very small in comparison). This profile has been derived from a multiple regression analysis of hourly wind values measured between 27 and 29 July 1994 by the MF radar at Tromsø, but it is restricted to the time-interval between 21 and 01 UT. The westward-directed wind below $86 \mathrm{~km}$ causes positive $\tau$, and the eastward-directed winds above $86 \mathrm{~km}$ negative $\tau$ values. However, the 


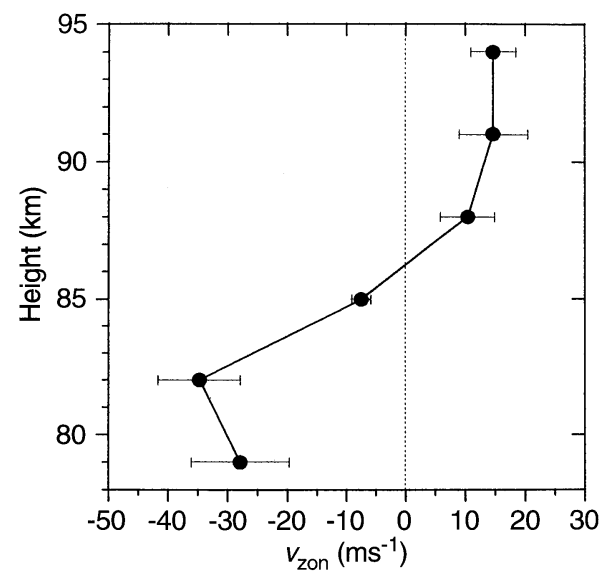

Fig. 14. Height profile of mean zonal wind deduced from MF-radar measurements carried out between 27 and 29 July 1994 between 21 and $01 \mathrm{UT}$

observed time-delays (Fig. 13) agree only qualitatively with the expected delays calculated from the MF wind profile. Wind speeds required to produce the crosscorrelation analysis values are about a factor of 2 larger than those in Fig. 14. The reason for this discrepancy is not known at this time. Kelley et al. (1990) speculate that the PMSE structures are not carried by winds but might be associated with a wave phase. If we assume a saturated wave with a phase speed equal to the wind speed then the velocity along the Tromsø-Andoya baseline (nearly east-west) should be twice the zonal wind speed for a $45^{\circ}$ propagation angle. This angle is supported by MF-radar observations with nearly equal zonal-meridional winds.

\subsection{Previous wind comparisons}

It must be noted that extensive system comparisons have been carried out (1987-1989) between Tromsø MF radar and rocket, SOUSY radar and EISCAT (Manson et al., 1992). In this earlier MF system, the MF wind magnitudes were found to be $35 \%$ reduced from other systems (directions and tidal phases were consistent between systems). At that time it was considered that low SNR problems due to minimal receiving antennas and amount of signal integration were affecting the analysis used to obtain wind vectors. Since that time, and including the observations discussed here, better antennas and improved receivers and analysis have brought the system quality closer to that at Saskatoon. This change is expected to have led to an increase in the estimated wind speeds. No significant difference in speeds was found in the Saskatoon FPI/MFradar wind comparisons mentioned in Sect. 3a (Phillips et al., 1994). The future ALOMAR SOUSY/Tromsø MF-radar wind comparisons will undoubtedly help to resolve this discrepancy. Other factors affecting the speed obtained from the PMSE structures include their actual orientation and advection direction, and temporal changes in the structures.

\section{Conclusions}

Using simultaneous observations of polar mesosphere summer echoes with three different radars in northern Norway during summer 1994, the following results were obtained:

- PMSE have been observed at 224 and $53.5 \mathrm{MHz}$. Also, at $2.78 \mathrm{MHz}$, we found strong indications of PMSE which are superposed, however, by the normal nonPMSE-caused partial reflections. The backscattered power of all three observations are significantly correlated.

- The zonal extent of PMSE is more than $130 \mathrm{~km}$.

- The detailed structure of PMSE is markedly modulated by waves (tidal and gravity), and PMSE structures are partly transported by the mean wind field.

Complex observations with different methods at nearly the same location, as well as observations with comparable equipment at different places are planned in future, in order to obtain more detailed information about the polar mesopause region in summer. This will lead to a better understanding of the structure and dynamic of this region in general and of the polar mesosphere summer echoes in particular.

Acknowledgements. The authors would like to thank D. Keuer and M. Zecha for assistance in operating the ALOMAR SOUSY radar, T. Holmboe for operating the Tromsø MF radar, and the staff of the Andoya Rocket Range for permanent support. The EISCAT Scientific Association is funded and operated by CNRS (France), SA (Finland), MPG (Germany), Norges Forskningsråd (Norway), NFR (Sweden) and PPARC (United Kingdom).

Topical Editor D. Alcaydé thanks J. Y. N. Cho and U.-P. Hoppe for their help in evaluating this paper.

\section{References}

Aso, T., Time-dependent numerical modelling of tides in the middle atmosphere, J. Geomagn. Geoelectr., 45, 41-63, 1993.

Balsley, B. B., R. F. Woodman, M. Sarango, R. Rodriguez, J. Urbina, R. Ragaini, J. Carey, M. Huaman, and A. Giraldez, On the lack of southern hemisphere polar mesosphere summer echoes, $J$. Geophys. Res., 100, 11685-11693, 1995.

Bremer, J., W. Singer, D. Keuer, P. Hoffmann, J. Röttger, J. Y. N. Cho, and W. E. Swartz, Observations of polar mesosphere summer echoes at EISCAT during summer 1991, Radio Sci., 30, 1219-1228, 1995.

Bremer, J., P. Hoffmann, W. Singer, C. E. Meek, and R. Rüster, Simultaneous PMSE observations with ALOMAR SOUSY and EISCAT VHF radar during the ECHO-94 campaign, Geophys. Res. Lett. 23, 1075-1078, 1996.

Cho, J. Y. N., and M. C. Kelley, Polar mesosphere summer radar echoes: observations and current theories, Rev. Geophys., 31, 243-265, 1993.

Cho, J. Y. N., and R. L. Morley, PMSE dependence on long-period vertical motions, Geophys. Res. Lett., 22, 1197-1200, 1995.

Cho, J. Y. N., T. M. Hall, and M. C. Kelley, On the role of charged aerosols in polar mesosphere summer echoes, J. Geophys. Res., 97, 875-886, 1992a.

Cho, J. Y. N., M. C. Kelley, and C. J. Heinselman, Enhancement of Thomson scatter by charged aerosols in the polar mesosphere: measurements with a $1.29 \mathrm{GHz}$ radar, Geophys. Res. Lett., 19, 1097-1100, 1992b.

Czechowsky, P., I. M. Reid, R. Rüster, and G. Schmidt, VHF radar echoes observed in the summer and winter polar mesosphere over Andoya, J. Geophys. Res., 94, 5199-5217, 1989. 
Ecklund, W. L., and B. B. Balsley, Long-term observations of the arctic mesosphere with the MST radar at Poker Flat, Alaska, $J$. Geophys. Res., 86, 7775-7780, 1981.

Hagfors, T., Note on the scattering of electromagnetic waves from charged dust particles, J. Atmos. Terr. Phys., 54, 333-338, 1992.

Hall, C. M., Modification of the energy-wave number spectrum for heavy proton hydrates as tracers for isotropic turbulence at the summer mesopause, J. Geophys. Res., 95, 5549-5556, 1990.

Havnes, D., U. de Angelis, R. Bingham, C. K. Goertz, G E. Morfill, and $\mathbf{V}$. Tsytovich, On the role of dust in the summer mesopause, J. Atmos. Terrr. Phys., 52, 637-643, 1990.

Hocking, W. K., Measurements of turbulent energy dissipation rates in the middle atmosphere by radar techniques: A review, Radio Sci. 20, 1403-1422, 1985.

Hoppe, U.-P., C. Hall, and J. Röttger, First observations of summer polar mesospheric backscatter with a 224-MHz radar, Geophys. Res. Lett., 15, 28-31, 1988.

Hoppe, U.-P., D. C. Fritts, I. M. Reid, P. Czechowsky, C. M. Hall, and T. L. Hansen, Multiple-frequency studies of the high-latitude summer mesosphere: implications for scattering processes, $J$. Atmos. Terr. Phys., 52, 907-926, 1990.

Hoppe, U.-P., T. A. Blix, T. V. Thrane, F.-J. Lübken, J. Y. N. Cho, and W. E. Swartz, Studies of polar mesosphere summer echoes by VHF radar and rocket probes, Adv. Space Res., 14, (9)139(9)148, 1994.

Ionospheric Absorption Data, Geophysical Observatory Sodankylä, The Finnish Acad. Science and Letters, July-August 1994.

Jensen, E. J., and G. E. Thomas, Numerical simulations of the effects of gravity waves on noctilucent clouds, J. Geophys. Res., 99, 3421-3430, 1994.

Kelley, M. C., D. T. Farley, and J. Röttger, The effects of cluster ions on anomalous VHF backscatter from the summer polar mesosphere, Geophys. Res. Lett., 14, 1031-1034, 1987.

Kelley, M. C., J. C. Ulwick, J. Röttger, B. Inhester, T. Hall, and T. Blix, Intense turbulence in the polar mesosphere: rocket and radar measurements, J. Atmos. Terr. Phys., 52, 875-891, 1990.

Kirkwood, S., J. Y. N. Cho, C. M. Hall, U.-P. Hoppe, D. P. Murtagh, J. Stegman, W. E. Swartz, A. P. van Eyken, G. Wannberg, and G. Witt, A comparison of PMSE and other ground-based observations during the NLC-91 campaign, J. Atmos. Terr. Phys., 57, 35-44, 1995.

Klostermeyer, J., The effect of ice particles on Thomson scattering from the polar summer mesopause region, Geophys. Res. Lett., 21, 2721-2724, 1994a.
Klostermeyer, J., A two-ion ice particle model of the polar summer mesopause, J. Geophys. Res., 99, 5487-5497, 1994b.

Manson, A. H., and C. E. Meek, Heights of MF radar scatter $(1986 / 87)$ and the wind field $(55-95 \mathrm{~km})$ : Saskatoon, Canada, $J$. Atmos. Terr. Phys., 51, 1003-1016, 1989.

Manson, A. H., C. E. Meek, A. Brekke, and J. Moen, Mesosphere and lower thermosphere $(80-120 \mathrm{~km})$ winds and tides from near Tromsø $\left(70^{\circ} \mathrm{N}, 19^{\circ} \mathrm{E}\right)$ : Comparisons between radars (MF, EISCAT, VHF) and rockets, J. Atmos. Terr. Phys., 54, 927-950, 1992.

Phillips, A., A. H. Manson, C. E. Meek, and E. J. Llewellyn, A longterm comparison of middle atmosphere winds measured at Saskatoon $\left(52^{\circ} \mathrm{N}, 107^{\circ} \mathrm{W}\right)$ by a medium-frequency radar and a Fabry-Perot interferometer, J. Geophys. Res., 99D, 12923-12935, 1994.

Röttger, J., Polar mesosphere summer echoes: dynamics and aeronomy of the mesosphere, Adv. Space Res., 14, (9)123-(9)137, 1994.

Röttger, J., C. La Hoz, M. C. Kelley, U.-P. Hoppe, and C. Hall, The structure and dynamics of polar mesosphere summer echoes observed with the EISCAT 224-MHz radar, Geophys. Res. Lett., 15, 1353-1356, 1988

Röttger, J., M. T. Rietveld, C. La Hoz, T. Hall, M. C. Kelley, and W. E. Swartz, Polar mesosphere summer echoes observed with the EISCAT 933-MHz radar and the CUPRI 46.9-MHz radar, their similarity to $224-\mathrm{MHz}$ radar echoes, and their relation to turbulence and electron density profiles, Radio Sci., 25, 671-687, 1990.

Rüster, R., Velocity and associated echo power variations in the summer polar mesosphere, Geophys. Res. Lett., 20, 65-67, 1995.

Taubenheim, J., Statistische Auswertung geophysikalischer und meteorologischer Daten, Akad, Verlagsgesellschaft Geest \& Portig K.-G., Leipzig, 1969.

Vlaskov, V. A., E. Turunen, and A. A. Bogolubov, Investigation of PMSE characteristics by partial reflection radar at $2.7 \mathrm{MHz}$, Paper GAB51F-01 presented at IUGG XXI General Assembly, Boulder, Colorado, 1995.

Williams, P. J. S., A. P. van Eyken, C. Hall, and J. Röttger, Modulations in the polar mesosphere summer echoes and associated atmospheric gravity waves, Geophys. Res. Lett., 16, 1437-1440, 1989.

Williams, P. J. S., G. O. L. Jones, J. R. Palmer, and H. Rishbeth, The association of polar mesosphere summer echo layers with tidal modes, Ann. Geophysicae, 13, 454-457, 1995. 